\title{
Study on the Role of Classical Literature in the Cultivation of College Students' Humanistic Quality
}

\author{
Su Jinling \\ Shaanxi Railway Institute, Weinan, Shaanxi, China, 714000
}

Keywords: classical literature; humanistic quality; cultivation

\begin{abstract}
Humanistic quality is one of the important indicators to measure the comprehensive quality of college students. A qualified college student not only requires a solid professional quality, but also needs a good humanistic quality. At present, Chinese colleges and universities pay more and more attention to the cultivation of college students' humanistic quality, and enrich students' humanistic knowledge by carrying out practical activities of humanities courses. With the deepening of education quality, China has been attaching more and more importance to the teaching of classical literature. Through the teaching of classic literature works, a healthy personality of students can be built, which is the unity of truth, goodness and beauty, and the unity of reason, will and emotion. Based on the reading of classic literature works, this paper further analyses the role of classic literature works on the cultivation of contemporary college students' humanistic quality, discusses how to cultivate their reading habits, improve their reading ability, and play an active role in cultivating and improving college students' humanistic qualities.
\end{abstract}

\section{Introduction}

Humanistic education has always been an important part of modern education. The essence of humanistic quality should be one's humanistic qualities. It includes respect for human nature and life, and the recognition and respect for human values, which are embodied in the humanities, humanistic spirit and humanistic behavior. The core content is the concern for human's value and survival significance. However, the inculcate and humanistic courses of college teachers cannot effectively cultivate the good humanistic quality of contemporary college students, nor can they fundamentally improve their humanistic quality. Therefore, this paper links classic literature works with college students' humanistic qualities, and studies the problems existing in the humanistic quality of contemporary college students from the perspective of classical literature works.From the perspective of classic literature works, the author puts forward the role of classical literature works to the cultivation of humanistic quality.

\section{The Significance of Cultivating Humanistic Quality of College Students}

\subsection{Improving the comprehensive quality of college students}

The comprehensive quality is reflected in the state of people's various abilities, and cultural knowledge and practical ability are indispensable to the comprehensive quality of college students. The comprehensive quality is not limited to these two aspects, the comprehensive quality is the overall embodiment of culture, nurture and ability. The comprehensive quality of college students mainly includes the quality of health psychology, correct values, human behavior, logical thinking, knowledge mastery, and pioneering and innovation. Good comprehensive quality is very important for college students. Therefore, for college students, it is necessary to strengthen their comprehensive qualities so that their value can be verified in a society with rapid development in the new period.

\subsection{Helpful for college students to achieve self-realization at the level of demand}

The cultivation of humanistic quality includes the correct attitude, the adjustment of state of 
mind and the clear goal is the premise of individual self-realization. The fundamental driving force of human development is self-realization and the highest goal of human being. Defining your goals and finding your own goals is something contemporary college students should consider first. College students should standardize themselves and set reasonable goals with high standards and strict requirements. In practice, strive for better goals. College students should learn self-control and adjustment. In the process of self-realization, they must correct their attitude and maintain a positive attitude. We should treat our studies with rigorous modesty and realistic attitude, and deal with other specific things with the correct understanding, rational judgment and careful method. A good attitude is to be well prepared for self-actualization.

\subsection{Helpful for forming a good campus culture atmosphere}

The specific mental and cultural atmosphere of the school is called campus culture. Campus landscape, campus building design, landscaping and so on belong to campus culture, The school's ethos, style, tradition, interpersonal atmosphere and norms and norms are also part of the campus culture. Healthy campus culture can enlighten students' minds and cultivate students' sentiment and promote their all-round development. The cultivation of humanistic quality promotes the construction of campus cultural environment, and the cultural environment plays an important role in the development of students. The campus environment plays an enlightening role in the student education, and the clean, beautiful, healthy and harmonious campus environment has a great influence on students' healthy growth and development. The school environment of beautification, purification and greening not only reflects the school spirit, but also reflects the good mental outlook of teachers and students. Every activity of the school should be permeated with cultural atmosphere and common cultural pursuit. The cultivation of humanistic quality promotes the creation of the spirit and culture of teachers and students, and the building of healthy and healthy campus culture atmosphere will undoubtedly influence the teachers and students' minds and produce a positive and upward force. The school's facilities and teaching resources increase students' access to society and the opportunity to learn about nature, allowing students to swim in the sea of knowledge.

\subsection{Helpful for improving the teaching quality of colleges and universities}

The improvement of teaching quality helps to strengthen the soft power of colleges and universities, and the teaching quality is the concentrated expression of the soft power of colleges and universities. The implementation of talent training is a major goal of education quality improvement in colleges and universities. In the knowledge-based economy society, colleges and universities undertake the task of cultivating the main force for culture and scientific and technological innovation. The soft power of colleges and universities, especially the quality of teaching, determines whether the university can accomplish the task of cultivating outstanding talents. The quality of teaching in colleges and universities determines the strength of the influence of the society, including its influence on the region, field and industry. This kind of influence is immeasurable, so improving teaching quality is crucial. Humanistic thought instructs teachers to pay attention to the guidance of students' learning methods, enrich the teaching situation, and increase the learning effect of students. The cultivation of humanistic quality improves the connotation construction of teaching course and the norm of course teaching elements, which is conducive to the reform of teaching methods, course content and evaluation methods. The cultivation of humanistic quality promotes the knowledge level of teaching teachers and outstanding young teachers, and improves the teaching quality and quality of students. Strengthen the practice link, pay attention to discover the innovation consciousness, realize the innovation talented person's training, can guarantee the teaching quality improvement. 


\section{The Role of Classical Literature in the Cultivation of College Students' Humanistic Qualities}

\subsection{Classical literature helps to improve the penetration of personality goals.}

The nature of Chinese discipline can't just talk about instrumental neglect of humanism, only really is to teach the language knowledge, train the ability of language, and to shape healthy personality, can make the students' language ability was improved, and real realize the value of the purpose of Chinese education, Chinese education. However, education is an important task of Chinese learning in high school. Literature aesthetics is an important field in which the Chinese subject is distinguished from the natural sciences. The teaching of classical literature works should have its own goal and content, and has the teaching method and process with individuality characteristic. The core should be the cultivation of literary appreciation ability and the formation of healthy personality.

\subsection{Classical literature can improve students' aesthetic ability.}

The key requirement of appreciation ability of literary works is to feel, taste, comprehend, experience and think. We can feel the image, taste the language, the rich connotation of the work, experience, and its own emotional experience and thinking. The dimension of process and method is permeated in the ability target, which demands the unity of sensibility and rationality, unity of subjectivity and objectivity, unity of emotion and thought, unity of content and form. The aesthetic ability is gradually improved in this process. By feeling the image and taste the language, the students will have their own experience and reflection on the rich connotation and artistic expression of the works. It is pointed out that "the cognitive analysis in the reading teaching of classical literature is still very popular," "physiological anatomy" and "information processing" form the main teaching methods of literature works. In this context, the teaching concept embodied in the above teaching cases is more precious. What we see here is a teacher's understanding and adherence to the language teaching concept, which is to spend more time on the words, We make the students gradually taste the article, step by step into the article, so as to improve the students' aesthetic ability, so that the students enjoy the most beautiful food of human spirit.

\subsection{Classical literature works encourage students' creative thinking.}

At present, the teaching of literature works in primary and middle schools has been criticized. Students haven't Yuan Wen Yuan poems, textbook "prompt" has the theme of the works, social significance, writing feature, etc., carrying out pour baskets of pouring basket, causes the student to fall down appetite and lose the interest of reading. It is difficult to have the pleasure of tasting the work, which is restricted in the circle of textbooks and teaching. Higher requirements in the teaching of classic literature is trying to explore works contain the national psychology and the spirit of The Times of understanding of human social life and emotional world, and then build the students' healthy personality. The excellent literary works of ancient and modern times, especially literary classics, are often both national and world. We need to have a deeper interpretation. Literary works of the writer's emotion, is not purely personal emotions, it is often the time spirit of refraction, even leads to a nation's national spirit, to the common cultural psychology of mankind .

\subsection{Classic literature works promote and cultivate the national spirit.}

It is the fundamental task of education to learn the classic literature works and to realize that the Chinese national spirit is to form a certain traditional culture. It is to cultivate the excellent offspring of Chinese nation with Chinese roots. In the face of the world's ideological and cultural interaction, it is necessary to carry forward and cultivate the national spirit as the most important task of cultural construction, including the whole process of national education. The national spirit will be the carrier of the national culture, and the national culture will be the quintessence of the outstanding language and literature works in Chinese history. The fundamental meaning of studying ancient literary works is here. Some people say that ancient poetry is a dead thing, it should be 
expelled from primary and secondary schools, it is an act of ignorance. But if learning ancient poetry is just to master the ancient Chinese language, it is easy to read ancient books. The classical literature we are talking about here is of course the language material for learning ancient Chinese. But they are first and foremost literary works, and they should make the target request from the perspective of literary appreciation. Through the study of classics, students are influenced by the excellent culture. To build the spiritual character of the college students who love the motherland and Chinese civilization and devote themselves to the cause of human progress. It is the true meaning and value of studying the classics of literature to form a healthy and beautiful emotion and a vigorous life attitude.

\section{Conclusion}

Reading classics is one of the most basic ways for students to acquire knowledge and complete their studies. The specialization of university study is stronger, and the knowledge system is more detailed. The study of Chinese courses alone can not meet the demands of college students nowadays, but many college students are not aware of this. Although the humanistic quality of college students is increasingly concerned by society, education and scholars, the state, universities and university teachers also take measures to better cultivate the humanistic quality of college students.

\section{References}

[1] Rob. Halsall. The President and Fellows of Harvard College. Report of the Task Force on General Education. Harvard University (2007), p. 35 - 46

[2] Drongelen K V, Bilderbeek J. Michalinos self-formation. Zembylas. Interrogating teacher identity: emotion, resistance and Educational theory (2008), p. 252-257

[3] Finke R A, Slayton K. Teacher Research and School Improvement. Open University Press (2008), p. 627 - 635

[4] Anders Lundstorm, Lois Stevenson. Entrepreneurship policy for the future. Swedish Foundation for small Business Research, Irwin (2013), p. 45-51

[5] Jock Collins. Cultural diversity and entrepreneurship: policy responses to immigrant entrepreneurs in Australia. Entrepreneurship and Regional Development (2012), p. 2-6

[6] Helge Berglann; EsPenR.Moen, KnutRoed, etal. Entre PreneurshiP: Originsand returns. Labour Eeonomies (2011), p. 180-193

[7] Roediger Voss. Thorsten Gruberjsabelle Szmigin."Service quality in higher education: Therole of student expectations". Journal of Business- Research (2007), p. 949-959 